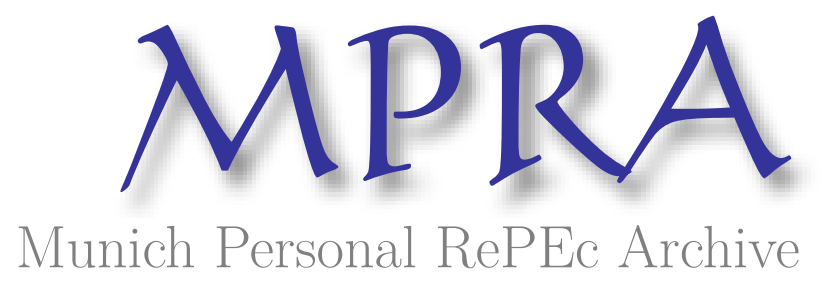

\title{
Picking a Winner? Evidence from the Non-Manufacturing High-Tech Industry in the Blacksburg MSA
}

Bieri, David

6 December 2006

Online at https://mpra.ub.uni-muenchen.de/1079/

MPRA Paper No. 1079, posted 07 Dec 2006 UTC 


\title{
Picking a Winner? Evidence from the Non-Manufacturing High-Tech Industry in the Blacksburg MSA
}

\author{
David S. Bieri*
}

This version: December 5, 2006.

\begin{abstract}
Regional scientists have developed numerous concepts and measures of economic diversity and diversification, primarily motivated by the desire to establish a relationship between diversity and economic performance. Rather than striving for a unified theory with a singular measure, this paper argues that economic developers should employ a multi-dimensional framework that combines the comparative advantages of a range of theoretical approaches. The application of locational, agglomerational and risk-reward measures to the nonmanufacturing high-tech industry for the Blacksburg MSA in southwestern Virginia reveals specific policy implications and offers lessons for economic policy design.
\end{abstract}

Key Words: Economic Development, Industry Concentration, Dispersion, Quantitative Measures.

${ }^{*}$ David Bieri is a Ph.D. student at the School of Public \& International Affairs at Virginia Tech, Blacksburg, VA 24060, USA. E-mail: dsb@vt.edu. 


\section{Contents}

1 Dimensions of economic activity 1

2 From Theory to Implementation 3

2.1 Basic Hypothesis . . . . . . . . . . . . . . . . 3

2.2 Additional Factors . . . . . . . . . . . . . . . . . . 4

3 A Comparison of Alternative Measures 5

3.1 Locational Measures . . . . . . . . . . . . . . . . . 5

3.2 Agglomeration Measures . . . . . . . . . . . . . . . 6

3.3 Risk-reward Measure . . . . . . . . . . . . . . . . . 7

4 Empirical Results $\quad 8$

4.1 The Blacksburg MSA . . . . . . . . . . . . . . . . . 9

4.2 Non-manufacturing High-Tech Industry . . . . . . . . . . 10

4.3 A hub-and-spoke cluster? . . . . . . . . . . . . 11

5 Policy Implications $\quad 12$

5.1 Elements of policy design . . . . . . . . . . . . . . 13

5.2 Directions for policy makers . . . . . . . . . . . . . 14

A Definition of Measures $r$

A.1 Locational Measures . . . . . . . . . . . . . . . . . . 19

A.1.1 Horizontal Clustering . . . . . . . . . . . . 19

A.2 Agglomeration Measures . . . . . . . . . . . . . . . . . . 19

A.2.1 Herfindahl-Hirschman Index . . . . . . . . . . . 20

A.2.2 Locational Gini Coefficient . . . . . . . . . . . 20

A.2.3 Ellison-Glaeser Index . . . . . . . . . . . . . 20

$\begin{array}{lr}\text { B Tables } & 21\end{array}$

$\begin{array}{lr}\text { C Figures } & 28\end{array}$ 


\section{Dimensions of economic activity}

Uneven development - both in space and over time - is one of the few constants across the many disciplines that investigate economic activity. From individual financial planning to macroeconomic management, the diverse efforts of policy makers are unified by the conviction that the disruptive potential of imbalances merits corrective action and intervention. Economic systems may display self-stabilising properties over the long-run, yet the associated social cost and time horizon are frequently deemed unacceptable.

In this context, policy makers regularly make an explicit distinction between efficiency and equity criteria. While the former are concerned with the allocation of scare resources that translates into economic growth, the focus of the latter is equitable economic development. Indeed, in trying to find a balance between these objectives, economic developers are often characterised as "Walrasian auctioneers with a normative conscience" (Polanyi, 1944).

There have been numerous attempts by regional scientists to develop concepts and measures of economic diversity and diversification, primarily motivated by the desire to establish a relationship between diversity and economic performance. ${ }^{1}$ Be it the core and periphery, the centre and the hinterland or leading and lagging regions, urban and regional planners apply a wide range of analytical concepts to distinguish between different shades of uneven development that describe the diverse realities of economic landscapes. The multiplicity and mutual overlaps of concepts and definitions

\footnotetext{
${ }^{1}$ See Siegel et al. (1995) for a comprehensive overview of the literature.
} 
might occasionally appear confusing, yet at the same time they serve as an important reminder that when analysing economic activity "one size does not fit all".

Rather than striving for a unified theory with a singular measure, this paper argues that economic developers should employ a multi-dimensional framework that combines the comparative advantages of a range of theoretical approaches. The combination of several quantitative measures of diversity affords policy makers a more comprehensive understanding of the dynamics and factors that shape regional economic activity - a key prerequisite for sustainable economic development. In many instances, however, this approach mightgive rise to contradictory signals that arise from different measures of concentration. Applying several such measures to the nonmanufacturing high-tech industry in the Blacksburg-Christiansburg-Radford Metropolitan Statistical Area ${ }^{2}$, I contend that even such apparent incongruities can provide valuable inputs for economic developers as part of a more rounded approach to fostering regional growth.

The remainder of this paper is structured as follows. Section II briefly discusses the challenge of economic development and outlines the theoretical background for different measures of concentration. Section III looks at the dimensions of three groups of quantitative measures, whereas section IV summarises the empirical findings of these metrics in the context of the non-manufacturing high-tech industry for the Blacksburg MSA. Section V reviews possible policy implications and offers some conclusions.

\footnotetext{
${ }^{2}$ Blacksburg MSA hereafter.
} 


\section{From Theory to Implementation}

In recent years, globalisation has raised old fundamental questions regarding economic development in a new context. Why are economic activity and prosperity spread so unevenly around the globe? Do trade and - more generally - spatial interaction necessarily narrow these differences? What explains the discrepancy between the predictions of theory and what happens in reality?

In response, policy debates in many industrialised countries have shifted their focus from international development issues to rising domestic regional inequalities. In the United States, for example, the analysis of regional disparities is beginning to feature high on institutional research agendas, even at federal agencies that do not have an explicit mandate to foster economic development, such as the Federal Reserve Banks (Yellen, 2006).

\subsection{Basic Hypothesis}

Economic base theory provides a widely-used starting point when analysing what makes cities and regions grow. It is founded on the tenet that external demand for a region's products is the primary determinant for regional prosperity, while endogenous demand - affecting growth through the multiplier - is of secondary importance. Distinguishing between basic and non-basic (or residentiary) industries, development strategies based on economic base theory focus primarily on increasing export growth, infrastructure developments and import substitution.

In this context, determining regional export activity is particularly im- 
portant and location quotients (LQs) are the most frequently employed measure of relative sectoral specialisation. While many extensions and refinements have been offered, economic base theory is generally faulted for being too coarse a tool for explaining the complexities of regional change. ${ }^{3}$

\section{$2.2 \quad$ Additional Factors}

Clearly, external demand is not the only exogenous driver of change nor do aggregated multipliers offer sufficient granularity to measure the dynamics of regional economic growth and decline. Ranging from theories of spatial concentration and neoclassical trade and growth theories to product cycle theories, theories of flexible production and clusters, and entrepreneurship theory, a vast array of literature is addressing the shortcomings of economic base theory. Broadly speaking, these theories deal with additional drivers of concentration and dispersion which can be summarised into the following, mutually non-exclusive categories:

- Agglomeration economies, ${ }^{4}$

- transportation, transaction and other input costs,

- changes over the product or the spatial life cycle, and

- sources of locational competitive advantages. $^{5}$

As economic base theory has been complemented by the emergence of these more elaborate models, the one-dimensionality of LQs has been supple-

\footnotetext{
${ }^{3}$ See for example the staple theory approach by North (1955) and its critique by Tiebout (1956).

${ }^{4}$ See Feser (1998) for a detailed overview of a variety of agglomeration concepts.

5Porter's "diamond" (2000), for instance, is based on firm context, input factor conditions, demand and supply conditions and knowledge spillovers.
} 
mented by a series of alternative measures of economic dispersion. The next section provides a tour d'horizon of the most widely cited such quantities.

\section{A Comparison of Alternative Measures}

Reflecting the fact that it would be futile to reduce complex dynamics to a singular metric, quantitative measure of regional economic activity are often complementary. While each addressing slightly different dimensions and frequently grounded in distinct theories, they can be largely grouped into two categories: locational and agglomeration measures. ${ }^{6}$

\subsection{Locational Measures}

As discussed above, LQs are a standard measure of employment distribution that controls for the size of the region. A value of greater than unity indicates that there is an above average proportion of employment in a given industry in a given region. Industries with a value above 1.25 are generally viewed as constituting the core of the export-oriented economic base. ${ }^{7}$

Although LQs are widely used, their main drawback is that they ignore any dimension of industry clustering within the region. In other words, LQs only measure the relative importance of an industry and do not provide a measure for the industry's absolute size in that region. This limits their use as a policy indicators since it is possible to obtain high LQs for very small

\footnotetext{
${ }^{6} \mathrm{~A}$ comprehensive definition and the mathematical formulæ for each of these measures is relegated to the appendix. Several of the agglomeration measures require county level data with the BLS unfortunately does not disclose for the high-tech industry. These measures are thus not computed in the empirical section.

${ }^{7}$ See e.g. Malizia and Feser (1999).
} 
local industries.

In order to capture the 'mass effects' of larger industries irrespective of relative concentration, Fingleton et al. (2004) propose a measure for horizontal clustering (HC). This measure accounts for possible agglomeration effects in terms of the numbers of jobs in a specific industry and is defined as the number of jobs that exceeds the expected number of jobs in the local industry if it had the same share as the national economy.

\subsection{Agglomeration Measures}

Locational measures do not address the geographic dispersion and uneven distribution of employment within subregions of an area under study. The Herfindahl-Hirschman index (HHI) is the most simple measure to overcome this specific shortcoming. While the HHI assumes that all subregions have the same area and it is sensitive to the number of firms in each industry, its main advantage stems from its computational simplicity.

The locational Gini coefficient (LGC) also accounts for agglomeration and concentration within a specific region, but in a most sophisticated way than the HHI. Commonly defined as the measure of the inequality of an industry's regional distribution, the LGC is the ratio of the mean of the difference between individual LQs and the mean LQ. It tends to be the most widely used measure of industrial concentration in the literature of the new economic geography. ${ }^{8}$

However, both the HHI and the LGC fail to reflect a firm's intentional locational selection. In other words, these measures do not distinguish whether

\footnotetext{
${ }^{8}$ See Krugman $(1991 ; 1995)$ for a comprehensive overview.
} 
industries occur at a specific location randomly, or on the basis of specific considerations, such as spill-over effects or natural advantages. Furthermore, these indices are not comparable across industries and regions. An increasingly popular index proposed by Ellison and Glaeser tackles these aspects and measures to what extent patterns of industrial concentration differ from a situation if firms had "chosen locations by throwing darts at a map" (Ellison and Glaeser, 1997, p.890). ${ }^{9}$

\subsection{Risk-reward Measure}

While locational and agglomeration measures account for different dimensions of uneven economic development, they are less useful to capture uneven development over time, particulary when focusing on employment growth. Indeed, employment growth is one of the most important criteria for economic developers when selecting target industries.

Drawing from financial theory and portfolio construction, Berry and Blackwell (2005) introduce a measure of employment variability. The socalled employment beta enables economic planners to consider the volatility of employment in combination with the growth of employment in target industries. Like investors who generally prefer the less volatile of two stocks with similar returns, this measure suggests that - given the choice between two industries with similar (historical) employment growth - policy makers are best advised to target the industry which exhibits less ups and downs in employment over the economic cycle.

Clearly, the individual assumptions behind these different measures make

\footnotetext{
${ }^{9}$ See Feser (2000) for a critical review of this measure.
} 
their cross-comparability highly dependent on the specific context in which they are applied. Indeed, the question regarding the most suitable measure of the geographic concentration of economic activity still remains a highly contentious issue (Spieza, 2003).

\section{Empirical Results}

Inspired by the success stories of Silicon Valley, Massachusetts' I-128 corridor and the Research Triangle in North Carolina, the high-tech industry has perhaps received more attention from economic developers than any other industry. Despite its limited share of overall employment in most regions (rarely exceeding 5\%), the high growth potential of technology intensive industries has become a central element in regional economic development. As the traditional manufacturing sectors in industrial countries have either matured or are declining, the theoretical and empirical focus of economic development has shifted to private and public sector high-tech organisations and non-profit research institutions. In this context, high-tech is often equivalent to high R\&D expenditures (Goldstein and Luger, 1993).

The American Electronics Association (2003) provides a widely used 6digit NAICS code definition of the high-tech industry which distinguishes between between manufacturing and non-manufacturing high-tech. As the performance of former is often inextricably linked to the presence of an oldeconomy manufacturing hub, the latter displays most of the characteristics which are associated with the knowledge-based new economy, receiving more attention in the literature as a result. 
Evidence from product cycle theory suggests that high-tech clusters are indeed cycle- or stage-dependent, which adds to the appeal of the nonmanufacturing high-tech industry as a natural target area for policy action. ${ }^{10}$ While both types of high-tech industries are present in the case of the Blacksburg MSA, I will therefore only focus on the non-manufacturing high-tech industry. Table 1 lists the relevant industries and their NAICS classification which are grouped into communication and software and technology services.

\subsection{The Blacksburg MSA}

The town of Blacksburg and the City of Radford each enjoy a dominant presence while the town of Christiansburg, and Pulaski and Giles counties are present in a more peripheral capacity. ${ }^{11}$ Manufacturing, as has been traditionally the case in southwestern Virginia, remains a key influence in the region's economy. Furthermore, Virginia Tech and Radford University are significant economic drivers within the area as well.

Table 2 confirms that employment in the Blacksburg MSA is strongly bipolar, with a heavy concentration in two key industries, Manufacturing (NAICS 31-33) and Educational Services (NAICS 61). Looking at employment within these industries reveals similar, hub-and-spoke industrial organizational structures in both poles; Volvo acting as the centre of a private sector, manufacturing-based hub and Virginia Tech (and to a lesser degree Radford University) as the center of a public-sector, educational hub.

\footnotetext{
${ }^{10}$ See e.g. Bresnahan et al. (2001).

${ }^{11}$ This outline of the economy and industrial structure of the Blacksburg MSA draws from Bieri et al. (2006).
} 
Figure 1 substantiates that both manufacturing and educational services display a level of specialization that significantly exceeds national and state levels, with education being marginally more specialized $(\mathrm{LQ}=2.23)$ than manufacturing $(\mathrm{LQ}=2.03)$.

\subsection{Non-manufacturing High-Tech Industry}

Employment in the non-manufacturing high-tech industry (NMHTI) in the Blacksburg MSA falls into two NAICS supersectors: Information (NAICS 51) and Professional and Technical Services (NAICS 54).

Table 3 illustrates that in 2005 some 1,670 jobs or $2.5 \%$ of the region's employment were accounted for by the NMHTI. ${ }^{12}$ Over $85 \%$ of the non-manufacturing high-tech employment is concentrated in software and technology services with computer, engineering and R\&D-related industries alone accounting for three-thirds. Combined with the fact that over twothirds of these jobs are concentrated in Montgomery county, this provides a first clear indication for the presence of possible agglomeration effects around Virginia Tech.

The two measures of dispersion (LQs and HCs) presented in table 4 reveal that the NMHTI has become increasingly specialised over the last decade. While there is some evidence of a shake-out in a few industries most likely connected to the burst of the internet bubble - the specialisation of the dominant players is particularly pronounced in engineering and R\&Drelated services, with LQs of 1.28 and 1.30 respectively. Furthermore, the HCs for these industries uncover increasing regional clustering which pro-

\footnotetext{
${ }^{12}$ This compares to the national average of $3.3 \%$.
} 
vides additional support for the presence of agglomeration forces. Indeed, in 2005 some $10 \%$ of the MSA's non-manufacturing high-tech employment shows explicit cluster characteristics. ${ }^{13}$

Overall, the evolution of the region's industry specialization from 1990 to 2005 reveals that the two economic powerhouses (education and manufacturing) have broadly maintained their positions and continue to form the economic base. At the same time, as is highlighted in figure 1 by the red and yellow bubbles, the NMHTI-based sectors unambiguously represent the area's emerging industries. Accordingly, figure $\mathbf{2}$ reveals that the regional wage gaps have been closing and that the catch-up rate does not appear to be related to the deviation from the national averages, but seems to reflect industry-specific and regional phenomena.

\subsection{A hub-and-spoke cluster?}

Much of the quantitative evidence presented thus far permits the inference that the location of NMHTI in the Blacksburg MSA is strongly influenced by the presence of Virginia Tech. While the high-tech industry may even thrive in the absence of a major research university (Mayer, 2005), the Blacksburg MSA does not seem to have bucked conventional wisdom.

The shift-share analysis of employment changes in the NMHTI offers additional evidence. Table 5 indicates that, whilst a large part of the job growth can be assigned to national factors, there are some notable exceptions. In particular, for the key industries identified above (i.e. computer,

\footnotetext{
${ }^{13}$ The HCs in table 4 bring to light that for engineering and R\&D there are almost 200 jobs in excess of what could be expected from the national industry norm.
} 
engineering and R\&D-related services) an overriding part of job creation arose due to local factors. This finding is certainly consistent with the hypothesis that Virginia Tech exerts substantial gravitational pull on the high-tech industry.

In summing up, we can reasonably assume that the spatial concentration of the NMHTI is best approximated by a hub-and-spoke model or even given that Virginia Tech is a public entity - by a state-anchored district. ${ }^{14}$ With a theoretical model of industrial organisation now corroborated by quantitative evidence, the following section discusses what this entails for policy makers.

\section{$5 \quad$ Policy Implications}

So far, the NMHTI in the Blacksburg MSA bears all the hallmarks of an emerging industry that is successfully clustering around one of the existing employment hubs in the region. In addition, the employment growth - one of the most important criteria for selecting target industries - illustrates that high-tech also means high-performance in this instance: over the last decade, NMHTI employment grew by a stellar $56.2 \%$, as opposed to the subpar growth of the rest of the MSA in comparison to the national average (9.4\% vs. $11.7 \%$, see table 5$)$.

Does this showcase evidence, however, automatically render the hightech industry a winner for economic developers? This question is inextricable linked to the issue of sustainability and a target industry's performance over

\footnotetext{
${ }^{14}$ This terminology follows Markusen (1996) who proposes three alternative concepts of industrial districts, namely hub-and-spoke, satellite platforms and state-anchored districts.
} 
the economic cycle.

\subsection{Elements of policy design}

In addition to location and agglomeration measures, therefore, the employment beta provides further useful insights for policy makers. In fact, table 6 reveals that the most dominant players in the NMHTI in the Blacksburg MSA have a historically high employment volatility. In combination with their high employment growth, however, this still permits the NMHTI to be classified as acceptable target industries for economic development.

The usefulness of this measure as a guide for policy direction is further illustrated by briefly looking at the manufacturing high-tech industry which is also present in the Blacksburg MSA, clustering around the second of its two hubs. In this case, by contrast, the unfavourable combination of low growth and high volatility strongly cautions against any pro-active targeting by planners.

While a complementary mix of measures of economic concentration are a critical tool for planners and developers, additional quantitative measures will further improve policy design. Indicators of innovation (e.g. the number

of patents) or entrepreneurial activity (e.g. firm size or wage growth) yield specific information that will enhance the effectiveness economic development initiatives. Table 7 highlights that NMHTI firms in the Blacksburg MSA are smaller than the national average. This might be an indicator for a high presence of start-ups in the region and warrant economic planners to focus on designated entrepreneurship policies. 


\subsection{Directions for policy makers}

Even if picking a winner is a necessary element of a successful region development plan, it is by no means a sufficient one. Particularly in the context the current debate which focuses extensively on the high-tech industry, two important elements with regard to the normative focus of the policy debate seem important. In most regions, high-tech employment is concentrated only in a few industry segments and - although a rapidly growing sector of the economy - employment in the high-tech industry is only a small fraction of the regional total. More broadly speaking, there are no quick wins in economic development, not even with high-tech. ${ }^{15}$

Policy makers also ignore specific industry and regional linkages at their own peril; as much as $20 \%$ of a region's observed geographical concentration can be explained by natural advantages in resources or labour markets (Ellison and Glaeser, 1999). Put differently, where there is no hub, spokes are unlikely to develop.

Good policies do not depend on good theory alone, they also rely on sound implementation - an aspect that seems all too frequently forgotten in practice (Wood, 2001). Be it simple const-benefit studies or more sophisticated modes of inquiry, like a cluster analysis, effective research should be designed with clear policy questions in mind and it should be transparent. In economic development policy making, good scientific practice is not grounded on quantitative measures alone, but relies on a prudent mix of

\footnotetext{
${ }^{15}$ Looking at the biotech industry in the US, Cortright and Mayer (2001; 2002) conclude that development of successful high-tech clusters requires considerable amounts of time and investment. Furthermore, success critically depends on the research capacity and the ability to convert research into commercial activity.
} 
quantitative (top-down) and qualitative (bottom-up) methods; measures of concentration and dispersion or input-output modelling ought to be complemented by interviews, surveys and focus groups (Feser and Luger, 2003). 


\section{References}

AEA (2003): Defining the High-Tech Industry: AeA's New NAICS-based Industry Classification, American Electronics Association, Washington, D.C.

Atkinson, R. D. (2002): "The 2002 State New Economy Index," New economy report, Progressive Policy Institute, Washington, D.C.

Berry, S. G., and C. C. Blackwell (2005): "The Employment Beta," Economic Development Journal, 4(3), 48-53.

Bieri, D. S., K. Fisher, S. Hartsfield, and C. Wong (2006): "Regional Audit: Blacksburg-Christiansburg-Radford MSA," Mimeo., School of Public \& International Affairs, Virginia Tech, Blacksburg, VA.

Bresnahan, T., A. Gambardella, and A. Saxenian (2001): "'Old economy' inputs for 'new economy' outcomes: Cluster formation in the new Silicon Valleys," Industrial and Corporate Change, 10(4), 835-860.

Cortright, J., And H. Mayer (2001): "High tech specialization: A comparison of high technology centers," Survey series, The Brookings Institution, Washington, D.C.

(2002): "Signs of life: The growth of biotechnology centers in the U.S.," Discussion paper, The Brookings Institution, Washington, D.C.

Ellison, G., and E. L. Glaeser (1997): "Geographic Concentration in U.S. Manufacturing Industries: A Dartboard Approach," The Journal of Political Economy, 105(5), 889-927.

(1999): "The Geographic Concentration of Industry: Does Natural Advantage Explain Agglomeration," American Economic Review, 89(2), $311-316$.

Feser, E. J. (1998): "Enterprises, External Economies and Economic Development," Journal of Planning Literature, 12(3), 283-302.

(2000): "On the Ellison-Glaeser geographic concentration index," Working paper, University of North Carolina.

Feser, E. J., And M. I. Luger (2003): "Cluster Analysis as a Mode of Inquiry: Its Use in Science and Technology Policy Making in North Carolina," European Planning Studies, 11(1), 11-24. 
Fingleton, B., D. C. Igliori, and B. Moore (2004): "Employment growth of small high-technology firms and the role of horizontal clustering: evidence from computing services and R\&D in Great Britain, 1991-2000," Urban Studies, 41(4), 773-799.

Goldstein, H. A., And M. I. Luger (1993): Theories of local economic development: Perspectives from across the disciplines chap. Theory and practice in high-tech economic development, pp. 147-171. Sage Publications, Newbury Park.

Krugman, P. R. (1991): Geography and Trade. The MIT Press, Cambridge, MA.

(1995): Development, Geography and Economic Theory, no. 6 in The Ohlin Lectures. The MIT Press, Cambridge, MA.

Malizia, E. E., ANd E. J. Feser (1999): Understanding Local Economic Development. Rutgers, State University of New Jersey, New Brunswick, second edn.

Markusen, A. R. (1996): "Sticky places in slippery space: a typology of industrial districts," Economic Geography, 72(3), 293-313.

Mayer, H. (2005): "Taking root in the Silicon Forest: The role of high technology firms as surrogate universities in Portland, Oregon," Journal of the American Planning Association, 71(3), 318-333.

NorTh, D. C. (1955): "Location Theory and Regional Economic Growth," Journal of Policial Economy, 63(3), 243-258.

POLANYI, K. (1944): The Great Transformation: the political and economic origin of our times. Holdt, New York.

Porter, M. E. (2000): "Location, Competition, and Economic Development: Local Clusters in a Global Economy," Economic Development Quarterly, 14(1), 15-34.

Siegel, P. B., T. G. Johnson, and J. Alwang (1995): "Regional Economic Diversity and Diversification," Growth and Change, 26(2), 261-278.

SpiezA, V. (2003): "Geographic Concentration of Production and Unemployment in OECD Countries," Working paper, OECD, Paris.

Tiebout, C. M. (1956): "Exports and Regional Economic Growth," Journal of Policial Economy, 64(2), 160-169. 
Wood, L. E. (2001): "From Theory to Implementation: An Analysis of the Appalachian Regionals Commission's Growth Center Policy," Environment and Planning A, 33, 551-565.

Yellen, J. L. (2006): "Income Inequality in the United States," Federal Reserve Bank of San Francisco Economic Letter, 2006(33-34), 1-4. 


\section{A Definition of Measures}

The various quantitative measures of economic concentration are defined in detail in this section.

\section{A.1 Locational Measures}

The location quotient (LQ) is the standard measure of employment distribution that controls for the size of the region. The relative concentration of industry $i$ in region $j$ is defined as

$$
L Q_{i}=\frac{\left(E_{i j} / E_{i n}\right)}{\left(E_{j} / E_{n}\right)}
$$

where, $E_{i j}$ is employment in industry $i$ in region $j, E_{j}$ is total employment in region $j, E_{i n}$ is national employment in industry $i$, and $E_{n}$ is total national employment. Thus, a LQ of greater than one indicates that there is an above average proportion of employment in a given industry in a given region. Industries with an LQ above 1.25 are generally viewed as constituting the export-oriented economic base.

\section{A.1.1 Horizontal Clustering}

Horizontal clustering $(\mathrm{HC})$ is an alternative measure that accounts for possible agglomeration effects in terms of the numbers of jobs in a specific industry. As such, it is the arithmetic equivalent to a bubble chart which accounts for an industry's gravitational pull over and above what is expected to occur at the national level. $\mathrm{HC}$ can then be written as

$$
H C_{i}=E_{i j}-\widehat{E}_{i j}
$$

where $\widehat{E}_{i j}=E_{j} \times \frac{E_{i n}}{E_{n}}$ by setting $\widehat{L Q}_{i}=1$.

\section{A.2 Agglomeration Measures}

Location measures generally ignore geographic dispersion and uneven distribution of employment within subregions of an area under study. Agglomeration measures are designed to overcome this shortcoming. 


\section{A.2.1 Herfindahl-Hirschman Index}

In the context of industry employment concentration within an MSA the simplest such measure is the Herfindahl-Hirschman Index (HHI). It is defined as

$$
H H I_{i}=\sum_{i=1}^{n} s_{i}^{2}
$$

where $s_{i}$ is simply industry $i$ 's LQ at the level of the subregion compared to the MSA and $n$ is the number of counties within the MSA. ${ }^{16}$ The index is equal to 1 if there is absolute concentration and it takes a value of $\frac{1}{n}$ if employment in the industry is equally dispersed across the MSA.

\section{A.2.2 Locational Gini Coefficient}

The locational Gini coefficient (LGC) also accounts for agglomeration and concentration within a specific region, but in a most sophisticated way than the HHI. It is defined as

$$
L G C_{i}=\frac{\sum_{i=1}^{n} \sum_{j=1}^{n}\left|x_{i}-x_{j}\right|}{2 n(n-1) \mu}
$$

where $x_{i}$ and $x_{j}$ are the LQs of industries $i$ and $j$ in each of the subregions, $\mu$ is the mean of the LQs in the MSA and $n$ is the number of counties.

\section{A.2.3 Ellison-Glaeser Index}

The Ellison-Glaeser index (EG) measures how industrial concentration patterns differ from a situation where firms in a purely random manner. The index is defined as follows

$$
E G_{i}=\frac{\sum_{i=1}^{n}\left(s_{i}-x_{i}\right)^{2}-\left(1-\sum_{i=1}^{n} x_{i}^{2}\right) \sum_{j=1}^{m} z_{j}^{2}}{\left(1-\sum_{i=1}^{n} x_{i}^{2}\right)\left(1-\sum_{j=1}^{m} z_{j}^{2}\right)},
$$

where $s_{i}, x_{i}$ and $n$ have the same definitions as above; $z_{i}$ is the share of the 6-digit NAICS subsector establishments in sector $j$ and $m$ is the number of 6 -digit subsectors.

\footnotetext{
${ }^{16}$ In the context of MSA-level data, counties are commonly assumed to be the subregions. For the Blacksburg MSA, we would set $n=4$ since it includes Giles, Montgomery, Pulaski counties and the city of Radford.
} 


\section{B Tables}

Table 1: AeA Definition of Non-Manufacturing High-Tech Industries (6-digit NAICS code) $)^{a}$

\begin{tabular}{|c|c|c|c|}
\hline NAICS & Industry Description & NAICS & Industry Description \\
\hline \multicolumn{4}{|c|}{ Communication Services } \\
\hline & \multicolumn{3}{|l|}{ Communications Services } \\
\hline 517110 & Wired Telecom Carriers & 517410 & Satellite Telecom \\
\hline 517211 & Paging Services & 517510 & Cable \& Other Program Distribution \\
\hline 517212 & Cellular \& Other Wireless Telecom & 517910 & Other Telecom \\
\hline 517310 & \multicolumn{3}{|l|}{ Telecom Resellers } \\
\hline \multicolumn{4}{|c|}{ Software and Tech Services } \\
\hline & \multirow{3}{*}{\multicolumn{3}{|c|}{$\begin{array}{l}\text { Software Publishers } \\
\text { Software Publishers } \\
\text { Computer Systems Design and Related Services }\end{array}$}} \\
\hline 511210 & & & \\
\hline & & & \\
\hline 541511 & Custom Computer Programming & 541513 & Computer Facilities \\
\hline 541512 & \multicolumn{3}{|l|}{ Computer Systems Design } \\
\hline & \multicolumn{3}{|l|}{ Management } \\
\hline 541519 & \multicolumn{2}{|l|}{ Other Computer Related Services } & \\
\hline 518111 & Internet Service Providers & 518210 & Data Processing, Hosting, \\
\hline 518112 & \multicolumn{3}{|l|}{ Web Search Portals } \\
\hline & \multicolumn{3}{|l|}{ Engineering Services } \\
\hline 541330 & \multicolumn{3}{|l|}{ Engineering Services } \\
\hline & \multicolumn{3}{|l|}{ RED and Testing Labs } \\
\hline \multirow[t]{3}{*}{541710} & R\&D in the Physical, & 541380 & Testing Laboratories \\
\hline & \multicolumn{3}{|l|}{ Engineering \& Life Sciences } \\
\hline & \multicolumn{3}{|l|}{ Computer Training } \\
\hline 611420 & \multicolumn{3}{|l|}{ Computer Training } \\
\hline
\end{tabular}

$a$ The AeA's NAICS-based definition of high-tech industries is widely accepted and has been adopted by third parties, including regional Federal Reserve Banks, the Brookings Institution, the Bureau of Labor Statistics, and foreign governments such as Israel and the United Kingdom. Sources: American Electronics Association (2003), New Economy Index (2002). 
Table 2: Blacksburg MSA employment by industry and region (2-digit NAICS code), 2005

\begin{tabular}{|c|c|c|c|c|c|c|c|}
\hline NAICS & Industry & National & State & "MSA Total & Montgomery & Giles & Pulaski \\
\hline 10 & Total, All Industries & $131,290,280$ & $2,931,592$ & 64,838 & 26,656 & 3,302 & 10,960 \\
\hline 11 & Agriculture, Forestry, Fishing \& Hunting & $1,170,492$ & 13,085 & 197 & $* * *$ & $* * *$ & $* * *$ \\
\hline 21 & Mining & 560,806 & 8,754 & 79 & $* * *$ & - & $* * *$ \\
\hline 22 & Utilities & 807,003 & 10,980 & 448 & $* * *$ & 151 & $* * *$ \\
\hline 23 & Construction & $7,459,865$ & 244,011 & 3,065 & 1,759 & $* * *$ & 463 \\
\hline $31-33$ & Manufacturing & $14,233,731$ & 295,846 & 14,237 & 5,211 & 1,250 & 6,047 \\
\hline 42 & Wholesale Trade & $5,752,442$ & 117,450 & 1,038 & 574 & 40 & $* * *$ \\
\hline $44-45$ & Retail Trade & $15,321,267$ & 419,291 & 7,632 & 4,957 & 737 & 1,392 \\
\hline $48-49$ & Transportation and Warehousing & $5,207,450$ & 105,030 & 1,243 & $* * *$ & 119 & 479 \\
\hline 51 & Information & $3,199,862$ & 93,321 & 689 & 363 & 51 & 181 \\
\hline 52 & Finance and Insurance & $5,939,872$ & 132,194 & 947 & 577 & 79 & 166 \\
\hline 53 & Real Estate and Rental and Leasing & $2,175,943$ & 58,924 & 746 & 524 & 16 & 92 \\
\hline 54 & Professional and Technical Services & $7,169,407$ & 329,893 & 2,272 & 1,637 & 171 & $* * *$ \\
\hline 55 & Management of Companies and Enterprises & $1,743,160$ & 73,845 & 442 & 378 & - & $* * *$ \\
\hline 56 & Administrative and Waste Services & $8,165,207$ & 203,622 & 2,729 & 1,787 & 15 & 653 \\
\hline 61 & Educational Services & $11,587,989$ & 49,804 & 12,761 & 269 & - & $* * *$ \\
\hline 62 & Health Care and Social Assistance & $15,842,763$ & 315,508 & 6,207 & 3,524 & 496 & $* * *$ \\
\hline 71 & Arts, Entertainment, and Recreation & $2,213,831$ & 44,320 & 835 & 327 & $* * *$ & 201 \\
\hline 72 & Accommodation and Food Services & $10,932,816$ & 285,359 & 5,621 & 3,746 & $* * *$ & 854 \\
\hline 81 & Other Services, Ex. Public Admin & $4,378,924$ & 124,941 & 1,724 & 1,023 & 177 & 432 \\
\hline 92 & Public Administration & $7,427,402$ & - & 1,927 & - & - & - \\
\hline 99 & Unclassified & 48 & 5,414 & 0 & - & - & - \\
\hline
\end{tabular}

a Source: BLS Quarterly Census of Employment and Wages; - = Not computed, $* * *=$ Not disclosed. 
Table 3: Blacksburg MSA employment by high-tech industry and region (6-digit NAICS code), $2005^{a}$

\begin{tabular}{|c|c|c|c|c|c|c|c|}
\hline NAICS & Industry & National & "MSA Total & "Montgomery & Giles & Pulaski & Radford \\
\hline 10 & Total & $4,305,796$ & 1,671 & 1,137 & $* * *$ & $* * *$ & $* * *$ \\
\hline 517110 & Wired Telecom Carriers & 506,651 & 195 & $* * *$ & $* * *$ & $* * *$ & $* * *$ \\
\hline 517211 & Paging Services & 20,015 & - & 一 & - & - & \\
\hline 517310 & Telecom Resellers & 135,172 & 6 & $* * *$ & - & - & - \\
\hline 517410 & Satellite Telecommunications & 16,341 & - & - & - & - & \\
\hline 517510 & Cable \& Other Program Distribution & 135,387 & 54 & $* * *$ & - & $* * *$ & $* * *$ \\
\hline 541511 & Custom Computer Programming & 526,179 & 233 & 227 & - & $* * *$ & $* * *$ \\
\hline 541512 & Computer Systems Design & 508,353 & 185 & 175 & $* * *$ & $* * *$ & $* * *$ \\
\hline 541513 & Computer Facilities Management & 56,001 & - & - & - & - & - \\
\hline 541519 & Other Computer Related Services & 105,722 & 2 & $* * *$ & - & - & - \\
\hline 518111 & Internet Service Providers & 100,157 & 17 & $* * *$ & $* * *$ & $* * *$ & - \\
\hline 518112 & Web Search Portals & 15,551 & - & - & - & - & - \\
\hline 611420 & Computer Training & 19,572 & - & - & - & - & - \\
\hline
\end{tabular}

${ }^{a}$ Source: BLS Quarterly Census of Employment and Wages; - = Industry not present, ${ }^{* * *}=$ Not disclosed 
Table 4: Comparative measures of dispersion for non-manufacturing hightech employment in the Blacksburg MSA (6-digit NAICS code), 1996-2005

\begin{tabular}{|c|c|c|c|c|c|}
\hline \multirow[b]{2}{*}{ NAICS } & \multirow[b]{2}{*}{ Industry Description } & \multicolumn{2}{|c|}{1996} & \multicolumn{2}{|c|}{2005} \\
\hline & & LQ & $\mathrm{HC}$ & LQ & $\mathrm{HC}$ \\
\hline 517110 & Wired Telecom Carriers & 0.67 & -101 & 0.78 & -55 \\
\hline 517212 & Cellular \& Other Wireless Telecom & 0.66 & -15 & 0.25 & -63 \\
\hline 517310 & Telecom Resellers & 0 & 0 & 0.09 & -61 \\
\hline 517510 & Cable \& Other Program Distribution & 0.85 & -8 & 0.81 & -13 \\
\hline 511210 & Software Publishers & 0.24 & -67 & 0.40 & -70 \\
\hline 541511 & Custom Computer Programming & 0.38 & -102 & 0.90 & -27 \\
\hline 541512 & Computer Systems Design & 0.76 & -39 & 0.74 & -66 \\
\hline 541519 & Other Computer Related Services & 0.52 & -20 & 0.04 & -50 \\
\hline 518111 & Internet Service Providers & 0.33 & -18 & 0.34 & -32 \\
\hline 518210 & Data Processing, Hosting, \& Related Services & 0.22 & -109 & 0.21 & -104 \\
\hline 541330 & Engineering Services & 1.05 & 17 & 1.28 & 114 \\
\hline 541710 & R\&D Physical, Engin., \& Life Sciences & 0.67 & -64 & 1.30 & 75 \\
\hline 541380 & Testing Laboratories & 0.78 & -13 & 0.50 & -35 \\
\hline
\end{tabular}

${ }^{a}$ Location quotients (LQ) are defined against the national base $(L Q>1.25$ indicates high specialisation), horizontal clustering (HC) are defined as the of jobs in excess of what would be expected on the basis of the concentration at the national level; positive values (highlighted in bold) indicate clustering within an industry. Sources: BLS Quarterly Census of Employment and Wages and author's calculations. 
Table 5: Non-Manufacturing high-tech employment shift-share analysis for the Blacksburg MSA (6-digit NAICS code), 1996-2005

\begin{tabular}{|c|c|c|c|c|c|c|c|}
\hline NAICS & Code Industry & 1996 & 2005 & Change & National & Industry & Local \\
\hline & Total, MSA employment & 59,330 & 64,904 & $9.4 \%$ & & & \\
\hline & Total, high-tech employment & 1,068 & 1,671 & $56.2 \%$ & 1,193 & 124 & 478 \\
\hline 517110 & Wired Telecom Carriers & 202 & 195 & $-3.5 \%$ & 226 & -56 & -31 \\
\hline 517212 & Cellular \& Other Wireless Telecom & 29 & 21 & $-2.8 \%$ & 33 & 25 & -12 \\
\hline 517310 & Telecom Resellers & 0 & 6 & - & 0 & 0 & 6 \\
\hline 517510 & Cable \& Other Program Distribution & 45 & 54 & $20.0 \%$ & 50 & 8 & 4 \\
\hline 511210 & Software Publishers & 21 & 47 & $124.7 \%$ & 24 & 5 & 24 \\
\hline 541511 & Custom Computer Programming & 62 & 233 & $276.3 \%$ & 69 & 31 & 164 \\
\hline 541512 & Computer Systems Design & 121 & 185 & $53.5 \%$ & 135 & 58 & 49 \\
\hline 541519 & Other Computer Related Services & 22 & 2 & $-90.9 \%$ & 25 & 3 & -23 \\
\hline 518111 & Internet Service Providers & 9 & 17 & $88.8 \%$ & 10 & 7 & 6 \\
\hline 518210 & Data Processing, Hosting, \& Rel. Serv. & 31 & 27 & $-12.9 \%$ & 35 & -5 & -8 \\
\hline 541330 & Engineering Services & 352 & 523 & $48.6 \%$ & 393 & 46 & 129 \\
\hline 541710 & R\&D Physical, Engin., \& Life Sciences & 129 & 326 & $153.0 \%$ & 144 & 27 & 182 \\
\hline 541380 & Testing Laboratories & 45 & 35 & $-22.2 \%$ & 50 & 6 & -15 \\
\hline
\end{tabular}

a Shift-share analysis attributes the total change in regional employment to different factors, namely a national share, the industry mix and local influences. Sources: BLS Quarterly Census of Employment and Wages and author's calculations. 
Table 6: Selected national industry groupings by employment growth and beta, $1990-2005^{a}$

\begin{tabular}{lccl}
\hline \hline \multicolumn{3}{c}{ Desirable Target Industries: High growth/low volatility } \\
NAICS & Growth & Beta & Industry Description \\
\hline 6113 & $3.48 \%$ & 0.31 & Colleges, universities, and professional schools \\
\multicolumn{5}{c}{} \\
Acceptable Target Industries: High growth/high volatility \\
NAICS & Growth & Beta & Industry Description \\
\hline 5415 & $7.63 \%$ & 4.38 & Computer systems design and related services* \\
5112 & $2.16 \%$ & 3.22 & Software publishers* \\
\multicolumn{5}{c}{ Acceptable Target } & Industries: Low growth/low volatility \\
NAICS & Growth & Beta & Industry Description \\
\hline 3345 & $-1.55 \%$ & 0.63 & Navigational, measuring, electrical and control instruments* \\
\multicolumn{5}{c}{} \\
Unacceptable Target Industries: Low growth/high volatility \\
NAICS & Growth & Beta & Industry Description \\
\hline 3344 & $1.28 \%$ & 4.07 & Semiconductor and other electronic components* \\
3361 & $0.59 \%$ & 6.15 & Motor vehicle manufacture \\
3343 & $-4.61 \%$ & 1.82 & Audio and video equipment manufacture* \\
\hline \hline
\end{tabular}

${ }^{a}$ High-tech industries are marked with an asterisk $(*)$. The employment beta relates the employment variability in a 4-digit NAICS industry to the employment variability of total non-farm employment. Industries with high employment betas are more vulnerable to layoffs and plant closings. Source: Berry and Blackwell 2005. 
Table 7: Average firm size and wage growth in the non-manufacturing hightech employment in the Blacksburg MSA (6-digit NAICS code), 1996-2005

\begin{tabular}{ll|rr|rr}
\hline \hline & & \multicolumn{3}{|c}{ Avg. Firm Size } & \multicolumn{3}{|c}{ Wage Growth $^{\dagger}$} \\
NAICS & Industry Description & Nation & MSA & Nation & MSA \\
\hline Total & 15 & 20 & $3.4 \%$ & $3.5 \%$ \\
& Total, high-tech & $\mathbf{1 3}$ & $\mathbf{1 0}$ & $\mathbf{4 . 4 \%}$ & $\mathbf{4 . 2 \%}$ \\
& & & & \\
517110 & Wired Telecom Carriers & 26 & 15 & $3.3 \%$ & $1.7 \%$ \\
517212 & Cellular \& Other Wireless Telecom & 18 & 3 & $3.7 \%$ & $-3.1 \%$ \\
517310 & Telecom Resellers & 18 & 6 & $2.8 \%$ & - \\
517510 & Cable \& Other Program Distribution & 38 & 14 & $3.8 \%$ & $6.3 \%$ \\
511210 & Software Publishers & 24 & 12 & $3.7 \%$ & $1 \%$ \\
541511 & Custom Computer Programming & 8 & 7 & $4.1 \%$ & $5.3 \%$ \\
541512 & Computer Systems Design & 8 & 8 & $3.3 \%$ & $6.0 \%$ \\
541519 & Other Computer Related Services & 7 & 2 & $3.6 \%$ & $3.6 \%$ \\
518111 & Internet Service Providers & 13 & 3 & $6.3 \%$ & $8.8 \%$ \\
518210 & Data Processing, Hosting, \& Related Services & 21 & 4 & $4.1 \%$ & $11.2 \%$ \\
541330 & Engineering Services & 14 & 16 & $3.6 \%$ & $3.1 \%$ \\
541710 & R\&D Physical, Engin., \& Life Sciences & 30 & 12 & $4.7 \%$ & $5.3 \%$ \\
541380 & Testing Laboratories & 17 & 9 & $4.4 \%$ & $6.2 \%$ \\
\hline \hline
\end{tabular}

${ }^{a}$ Average firm size is defined as the total average employment divided by the average number of establishments; $\dagger$ Average annual wage growth from 1996 to 2005, with annual compounding; $-=$ Not computed. Sources: BLS Quarterly Census of Employment and Wages and author's calculations. 


\section{Figures}

Figure 1: Structural Changes and Economic Development within the Blacksburg-Christiansburg-Radford MSA, 1990 vs. $2005^{a}$

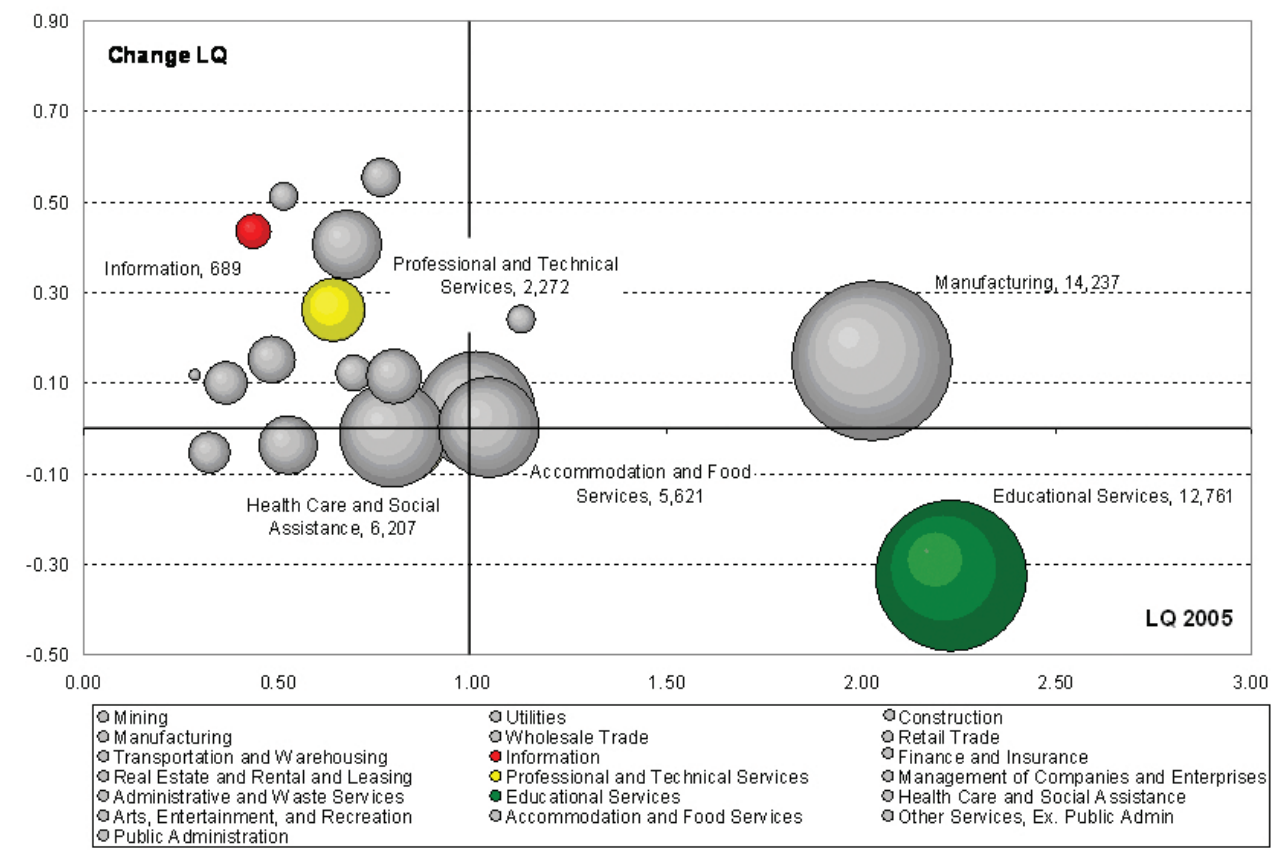

${ }^{a}$ Size of the bubbles is the average employment per 2-digit NAICS industry in 2005. Sources: BLS Quarterly Census of Employment and Wages and author's calculations. 
Figure 2: Development of nominal wages within the BlacksburgChristiansburg-Radford MSA, 1990 vs. $2005^{a}$

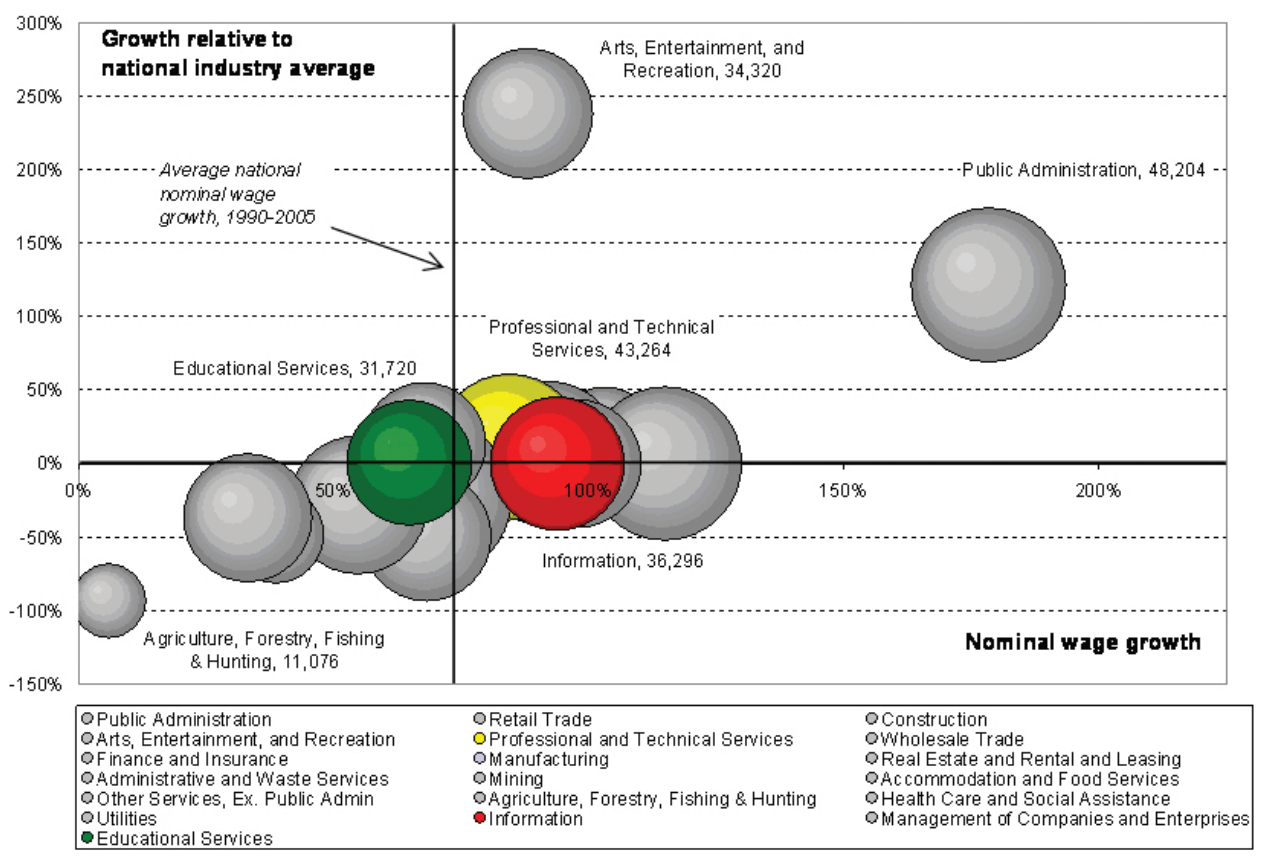

${ }^{a}$ Size of the bubbles is the average annual industry wage in nominal US $\$$ terms. In a number of key industries the regional wage gap is closing from 1990 to 2005 . The catch-up rate is not related to the deviation from the national averages, but seems to reflect industry-specific and regional demand and supply determined phenomena. Sources: BLS Quarterly Census of Employment and Wages and author's calculations. 